\title{
Methodological approach of Sport and Health for Overweight children (SHOW) intervention study
}

\section{Descrição metodológica do estudo de intervenção Sport and Health for Overweight children (SHOW)}

\section{AUTHOR'S \\ Gabriel Gustavo Bergmann ${ }^{1}$ (D) \\ Lorena Rodrigues Silva ${ }^{1}$ (D) \\ Franciéle da Silva Ribeiro ${ }^{1}$ (D) \\ Vivian Hernandez Botelho ${ }^{1}$ (D) \\ Gabriel Barros da Cunha ${ }^{1}$ (D) \\ Gustavo Dias Ferreira ${ }^{1}$ (D) \\ Eraldo dos Santos Pinheiro ${ }^{1}$ \\ 1 Universidade Federal de Pelotas, Departamento de Educação Física, Pelotas, Rio Grande do Sul, Brazil.}

\section{CORRESPONDING}

Gabriel Gustavo Bergmann

gabrielgbergmann@gmail.com

Universidade Federal de Pelotas (UFPel),

Escola Superior de Educação Física (ESEF/

UFPel)

Rua Luís de Camões, 625 - Três Vendas,

Pelotas, Rio Grande do Sul, Brazil.

ZIP CODE: 96055-630.

DOI

$10.12820 /$ rbafs.26e 0224

\section{(cc) BY}

This work is licensed under a Creative Commons Attribution 4.0 International License.

\begin{abstract}
Prevention and treatment of overweight among children have been a global challenge. A better understanding of different interventions to improve overweight children's health is needed. This paper describes the methodological approach of Sport and Health for Overweight children (SHOW) study, which investigated the effects of a multicomponent intervention on health markers of overweight children. The SHOW study is a non-randomized clinical trial performed during 16 weeks enrolling 72 overweight children aged eight to 12 years in an intervention $(\mathrm{IG}=35)$ and control group $(\mathrm{CG}=37)$. It is a multicomponent intervention program including generalized sport initiation, health education, and weekly communication between parents and researchers. Besides characterizing the participants', several health outcomes were analyzed in the SHOW study. Primary outcomes were accelerometer based physical activity and anthropometric indicators of overweight and obesity. Secondary outcomes were made up of cardiometabolic, fitness, behavioral, and psychological health indicators. We hypothesize that the SHOW study improves health outcomes and can be replicated in other settings as well as implemented by public policies.
\end{abstract}

Keywords: Child; Obesity; Physical activity; Health education; Clinical trial.

RESUMO

A prevenção e o tratamento do excesso de peso em crianças tem sido um desafio global. O melhor entendimento sobre diferentes propostas de intervenções que objetivem a melhoria do perfil de saúde de crianças com excesso de peso é necessário. $\mathrm{O}$ objetivo deste artigo foi descrever os procedimentos metodológicos do estudo Sport and Health for Overweight children (SHOW) que teve como objetivo investigar os efeitos de uma intervenção multicomponente sobre marcadores de saúde de crianças com sobrepeso. O estudo SHOW é um ensaio clínico não randomizado realizado durante 16 semanas envolvendo 72 crianças com sobrepeso de oito a 12 anos de idade alocadas em grupo intervenção $(\mathrm{GI}=35)$ e controle $(\mathrm{GC}=37)$. Trata-se de um programa de intervenção multicomponente composto por iniciação esportiva generalizada, educação em saúde e comunicação semanal entre pais e pesquisadores. Além da caracterização dos participantes vários desfechos em saúde foram analisados. Os desfechos primários foram atividade física medida por acelerometria e indicadores antropométricos de sobrepeso e obesidade. Os desfechos secundários foram compostos por indicadores cardiometabólicos, de aptidão física, comportamentais e psicológicos. Nossa hipótese é que a proposta de intervenção do SHOW melhorará os desfechos em saúde podendo ser replicada em outros ambientes e implementada por políticas públicas.

Palavras-chave: Criança; Obesidade; Atividade física; Educação em saúde; Ensaio clínico.

\section{Introduction}

The increase of overweight children prevalence has been reported in different parts of the world over the past decades ${ }^{1}$. A recent meta-analysis has shown that many interventions have been performed to reduce body weight and improve health markers in overweight children. However, results of these studies are not consistent ${ }^{2}$. As overweight is a condition influenced by multiple factors, strategies for prevention and treatment should also consider different factors ${ }^{2}$. In this sense, interventions including physical activity (PA), health education, and parents' participation have shown more favorable results ${ }^{2-4}$.

The participation of parents in health promotion interventions for overweight children is an important component to increase motivation, encouragement, and support to children's adherence to the intervention program ${ }^{2}$. Besides, the interest and engagement of 
overweight children's parents seem to be greater when interventions do not focus on weight loss but on general health issues ${ }^{5}$. The inclusion of health education may increase children's knowledge about the benefits of a healthy lifestyle and contribute to behavior changes which may improve different health markers ${ }^{4}$.

Regular PA practice benefits different health markers in children ${ }^{6}$, which may also be achieved for overweight children independent of weight loss $^{3}$. Sports are one of the main types of PA performed by children regardless of the setting and social context ${ }^{7}$. Since they consider sports more fun than other PA, this fact may increase motivation to practice ${ }^{8,9}$. Some studies $^{8,10,11}$ have used sports practice as an alternative to PA in interventions for overweight children, and results have shown improvements in several health markers. In addition to the scarcity of studies, investigations have used only one sport modality, specifically soccer, in interventions ${ }^{8,10,11}$. Thus, there is little evidence of the effects of interventions that include generalized sport initiation on health markers of overweight children.

In this sense, the availability of study protocols analyzing the effects of interventions involving the practice of different sports, health education, and participation of parents on health markers of overweight children may contribute to a better understanding of strategies to improve this population's health. This study aims to describe the methodological approach of Sport and Health for Overweight children (SHOW) study with a general objective to investigate the effects of a multicomponent intervention on health markers of overweight children.

\section{Methods}

The SHOW study is a non-randomized, open, parallel, and two-arm clinical trial. It was performed for 16 weeks from July to December 2019, enrolling overweight children aged between eight and 12 years from Pelotas, a southern city in Brazil. It comprised 32 programed sessions of 60 minutes of duration carried out twice a week on nonconsecutive days. Three Physical Education professionals conducted the sessions. The trial is registered in the Brazilian Clinical Trial Records (RBR-5ztpqs), approved by an Ethics Committee (4.127.321 / CAAE: 15719119.2.0000.5313), and reported, as closely as possible, according to the SPIRIT Statement ${ }^{12}$. SHOW is a multicomponent intervention program including generalized sport initiation, health education, and weekly communication between parents and researchers. It was developed based on the theory of Self-Determination ${ }^{13}$ to stimulate the mechanisms of behavior change associated with the levels of motivation and engagement.

The study was carried out in a partnership between the research team, the municipal education and sport (MESD), and health (MHD) departments starting in October 2018. The MESD intended to perform sports and PA programs initially for children in a neighborhood in which a public square (Unified Arts and Sports Center - UASC Square) had recently been built. The square is located close to two municipal public schools and consists of a covered multi-sports court and other facilities for leisure activities.

The proposal for the PA program was characterized as an intervention research project to be held over 16 weeks. The intervention program would be based on sports practices, carried out in the UASC, and offered to students of the two municipal public schools in the neighborhood on the opposite shift of school classes.

Representatives from the Programa Saúde na Escola and Basic Health Unit of the neighborhood, both linked to the MHD, expressed concern and interest that actions were aimed at overweight schoolchildren. We established a timetable to assess nutritional status of the students from the two schools of the neighborhood. Between April and May 2019, 493 students (from a total of 835) from both schools were assessed. Following standardized procedures ${ }^{14}$, body weight and height were assessed, and body mass index (BMI) was calculated. Among all measured students, 34.7\% were classified as overweight, obese, or severe obese ${ }^{15}$. Most of them were aged between eight and 12 years old (52.6\%). This information helped the research team, MESD and MHD representatives to decide that overweight children (including overweight, obese and severe obese) aged between eight and 12 would participate in the intervention program allocated in the intervention group (IG).

Considering the characteristics of the intervention program, the term SHOW was chosen as the program's name. In Brazilian slang, SHOW refers to something positive, motivating, and fun. In addition, the acronym in English refers to the type of intervention performed (sports), the outcome of the study (health), and the public who would be assisted (overweight children).

The SHOW study was also composed of a control group (CG) from a municipal public school in a different neighborhood with similar sociocultural features. 
The research team explained the SHOW's procedures and the characteristics of a CG to the school representatives, and a timetable for carrying out the nutritional status survey of the students was defined. In June 2019, a total of 266 children were assessed. Among them, 112 students (42.1\%) were classified as overweight, and 95 were aged between eight and 12 years old.

The decision for selecting children enrolled in a different neighborhood to compose the CG was taken to reduce contamination bias. As the intervention program activities would be performed at an open public space (UASC Square), if participants of the CG lived close to the square, they could be stimulated to practice PA and sports by the activities that were being performed at the UASC Square. They could spontaneously request to participate in the activities. In addition, if participants from both groups would study at the same schools, those from the IG could stimulate those from CG to practice PA demonstrating and talking about the activities and games that they were practicing at the sessions of the intervention program. We decided to choose a school also from a high social vulnerability neighborhood so that participants of both groups presented similar social characteristics.

The generalized sport initiation was elaborated based on two proposals of teaching sports/games for children ${ }^{16,17}$. These proposals consist in sports teaching centered on the features that make up the games, stimulating the learning of basic tactical principles of the games through the needs of making decisions related to "what to do", "how to do," and "when to do" in different situations of the games. The session formats were divided into three phases (Chart 1).

The progression of the generalized sport initiation during the 32 sessions was planned based on the increasing complexity of the activities used to improve basic tactical skills related to the $\mathrm{TICG}^{16}$. The complexity of the activities as hit the target, controlling and transporting the ball (and other objects), recognizing spaces, creating numerical superiority, overcoming the opponent, and leaving the mark increased based on pressure factors that make up the games, such as time, organization, complexity, precision, variability, and load. In this regard, the progression of the sessions was carried out methodologically from what the participants already knew to more difficult tasks (from known facts to unknown ones). This progression was performed by adding more complex activities with the implementation of new elements as the objectives of the sessions were achieved. It should be noted that participants were constantly encouraged to be autonomous to solve problems. Participants were asked about the solution to the problems that happened during games (what to do? how to do? and when to do?), and feedback was provided during the activities and after the end of the sessions.

The SHOW intervention program also consisted of orientations regarding health and well-being (Health Education). We presented specific health topics each week, which were socially contextualized and discussed at the end of each session. Ten different health topics were part of the health education program, with one topic addressed each week (two consecutive sessions). The ten addressed health topics were the following: the importance of washing hands; drinking water; respecting people; keeping physically active; eating well; controlling weight; having positive thoughts; sleeping

Chart 1 - Description of the general format of the intervention sessions of the SHOW study.

SHOW's Intervention Sessions - Initial Moment

At the beginning of the meeting, all children were in the center of the court to talk about what was performed in the last session and what would be performed in the current one. Subsequently, stretching and mobility exercises, active games already known and proposed by the participants themselves were carried out as warm-up activities. The initial moment of the sessions lasted about ten minutes.

$$
\text { SHOW's Intervention Sessions - Second (main) Moment }
$$

This moment lasted about 35 to 40 minutes. It was elaborated to improve basic tactical skills through games (called Tactical Intelligence and Creativity Games - TICG ${ }^{16}$ ) and improve coordinative abilities. To improve tactical skills, the TICG were based on the common elements of team sports providing different motor experiences. It is important to highlight that games were organized including features of different sports modalities. Thus, the adopted model of sports teaching in the SHOW study was not centered on only one sport modality. It was characterized as generalized sport initiation. During the performance of these games and all intervention, changes in the strategies and structure of the games were used. Changes in game situations as numerical superiority and inferiority and changes in the structure as changing rules and inserting and/or removing implements were used to encourage tactical creativity, decision-making and problems-solving capacity. We used several motor skills activities related to different sports modalities to improve coordinative abilities, such as ball passing and receiving using the feet and hands, kicking, dribbling, throwing, hitting, volleying, and shooting. These activities were performed individually, in pairs, and small groups using different objects, mainly balls of different dimensions, and performed based on different dynamics.

SHOW's Intervention Sessions - Final Moment

There was a meeting with all participants at the end of each session at the center of the court. It consisted of low-intensity activity, stretching exercises, and a conversation about what was performed during the session and what would be performed in the next session. In addition, this moment of the sessions was also used to talk about health orientations (health education). The final moment of the sessions lasted for about ten to 15 minutes. After the end of each session, physical education professionals met, talked, and evaluated the session. The main considerations were recorded in the SHOW study diary and considered for planning the following sessions of the intervention program. 
well and enough; reducing screen time; being aware of the harm caused by consuming alcohol; using tobacco, and using drugs. The topics that generated more interest among participants were addressed again completing the 16-week intervention program. In addition to conversations between participants and the research team, activities also consisted of experiences reported by the participants, memory games, and activities about the topics that were asked to be performed at home. Some of these activities should have been performed with the parents and/or other family members. The health education program was based and adapted from FIFA 11 for Health ${ }^{18}$.

During the intervention program, there were interactions between GI participant's parents and the research team (Communication between Parents and Researchers). Communication took place based on two main strategies. The first strategy used a group in an instant messaging app to establish communication between parents and research team making it possible to exchange information about children, about the intervention program activities, and their daily life. Parents were encouraged to interact with their children concerning the program using this app. They were suggested to talk to the children about what was done during the intervention sessions, to carry out with them the activities that were requested to be performed at home, and to motivate them and provide support within their possibilities so that they would participate in the program, and maintain regular attendance. The second communication strategy was a direct conversation with parents when they dropped off and picked up their children at the intervention program sessions. On these occasions, the same topics covered on the messaging app were discussed in person with the parents. However, in these opportunities, conversations were deepened. Shortly after the end of the conversations, we would note down the main points in the SHOW study diary.

Children from the CG did not participate in the intervention program and were instructed to perform their daily activities normally. Parents of the children from the $\mathrm{GC}$ were informed that an extracurricular sports project, according to the characteristics of the SHOW study, would be offered to overweight students from the school starting in March 2020. Additionally, we created a group in an instant messaging app to maintain communication between the research team and parents of CG children.

Once a week, we sent messages reminding the im- portance of the frequency at the program sessions to the parents of the IG children using the instant messaging group. When a child did not attend two consecutive intervention sessions, we would contact parents by phone. Every two weeks, we would send a message thanking the parents for the trust and effort provided to their children to participate in the intervention program. Additionally, children were constantly reminded about the importance of attending the sessions. Children were also questioned about the reasons for not attending the sessions. This strategy was important as it helped the research team better understand the main reasons for missing intervention program sessions. For the $\mathrm{CG}$, participants' retention strategy was to send a message to parents using the instant messaging group every four weeks, thanking them for allowing the children to participate, and a reminder that tests and measures would be carried out again at the end of the year (second week of December), and that an extracurricular sports project would be offered in the following year. A month before the post-intervention tests, we sent weekly messages, and three days before the post-intervention tests, we sent the same messages daily.

All measures included in the SHOW study were assessed one week before (pre) and one week after (post) the intervention program period, following the same procedures in both moments (pre-and post-intervention) and groups (IG and CG). Trained evaluators took the measurements, and they did not know which children were part of the IG or CG and did not participate in the intervention sessions (Table 1).

Participants were characterized by gender, age, height, body weight, nutritional status, somatic maturity, and family income. Age was calculated considering the dates of birth and collected dates. Height was measured with a portable stadiometer (Sanny, São Bernardo do Campo, Brazil) to the nearest 0.1 centimeters $(\mathrm{cm})^{14}$. Body weight was measured with a portable digital scale (Plenna, São Paulo, Brazil) to the nearest 0.1 kilograms $(\mathrm{kg})^{14}$. Height and body weight measurements were taken with the child dressed in light clothing and without shoes. Nutritional status (overweight, obesity, and severe obesity) was considered through the body mass index (BMI) classification ${ }^{15}$. The somatic maturity was measured by estimating the participants' distance (years) from the peak height velocity $(\mathrm{PHV})^{19}$. Family income was assessed by parents' report of family monthly minimum wages.

Health markers of the SHOW study were organ- 
Table 1 - Time scheme for enrollment, interventions, and assessments of SHOW study.

\begin{tabular}{|c|c|c|c|c|c|}
\hline \multirow[b]{3}{*}{ Timepoint } & \multicolumn{5}{|c|}{ Study period } \\
\hline & \multirow{2}{*}{$\frac{\text { Enrollment }}{-t_{1}}$} & \multirow{2}{*}{$\frac{\text { Baseline measures }}{\mathrm{t}_{0}}$} & \multicolumn{2}{|c|}{ Post-allocation } & \multirow{2}{*}{$\frac{\text { Close out }}{t_{4}}$} \\
\hline & & & $\mathrm{t}_{2}$ & $t_{3}$ & \\
\hline Timepoint description & Interviews & Measures & Intervention start & Intervention end & Measures \\
\hline \multicolumn{6}{|l|}{ Enrollment } \\
\hline Setting and population definition & $\mathrm{x}$ & & & & \\
\hline Eligibility screening & $\mathrm{x}$ & & & & \\
\hline Parents/guardians informed consent & $\mathrm{x}$ & & & & \\
\hline Groups (IG and CG) definitions & $\mathrm{x}$ & & & & \\
\hline \multicolumn{6}{|l|}{ Interventions } \\
\hline IG & & & $\mathrm{x}$ & $\mathrm{x}$ & \\
\hline \multicolumn{6}{|l|}{ CG } \\
\hline \multicolumn{6}{|l|}{ Assessments } \\
\hline \multicolumn{6}{|l|}{ Primary outcomes } \\
\hline Accelerometer based PA & & $\mathrm{x}$ & & & $\mathrm{x}$ \\
\hline Anthropometric measures & & $\mathrm{x}$ & & & $\mathrm{x}$ \\
\hline \multicolumn{6}{|l|}{ Secondary outcomes } \\
\hline Cardiometabolic health indicators & & $\mathrm{x}$ & & & $\mathrm{x}$ \\
\hline Fitness health indicators & & $\mathrm{x}$ & & & $\mathrm{x}$ \\
\hline Behavioral health indicators & & $\mathrm{x}$ & & & $\mathrm{x}$ \\
\hline Psychological health indicators & & $\mathrm{x}$ & & & $\mathrm{x}$ \\
\hline
\end{tabular}

$\mathrm{IG}=$ Intervention group; $\mathrm{CG}=\mathrm{Control}$ group; $\mathrm{PA}=$ Physical activity

ized in primary and secondary outcomes. Primary outcomes were accelerometer-based PA and anthropometric indicators of overweight (AIO), and secondary outcomes comprised cardiometabolic, fitness, behavioral, and psychological health indicators (Chart 2).

The inclusion criteria for selecting participants for the SHOW study were: children who were between eight and 12 years and nutritional status classified as overweight, obese or severe obese ${ }^{15}$. We considered as exclusion criteria physical or intellectual disabilities that prevented the practice of $\mathrm{PA}$ and / or comprehension to carry out the study measures. However, it is important to highlight no children met the exclusion criteria.

Parents of all children aged between eight and 12 classified as overweight, obese and / or severe obese were contacted and invited to meet the research team. Parents of the children enrolled at the two municipal public schools where IG participants would be selected were informed about the objectives, procedures, days of the week, and starting and finishing times for the intervention program sessions. Finally, the starting date of the activities was scheduled, and we also explained that parents and children would need to sign the informed consent form formalizing the children's participation in the intervention program. After all these steps, 35 children were part of the IG.

At the municipal public school where participants of CG were selected, the objectives and procedures of the SHOW study were presented to the parents. Characteristics of a $\mathrm{CG}$ were explained. It was informed that the research team and the representatives of the school's direction would structure an extracurricular sports project according to SHOW's characteristics to be offered to overweight students of the school from March 2020. After these steps, 37 overweight children composed the CG. A total of 72 overweight children, 35 in the IG and 37 in the CG, were enrolled in the SHOW study. Figure 01 summarizes the steps to select the participants of the SHOW study.

Considering that the SHOW study comprises several outcomes (primary and secondary), the sample size estimation was based on the following characteristics: a) two way ANOVA for repeated measures as the statistic reference test; effect size of 0.1 ; c) statistical significance (alpha) of 0.05 ; d) power (beta) of 0.8 (80\%); e) two groups (IG and CG) and four measures 
Chart 2 - Primary and secondary health outcomes of SHOW study.

\begin{tabular}{|c|}
\hline Primary Health Outcomes \\
\hline Accelerometer Based Physical Activity \\
\hline $\begin{array}{l}\text { Measured using wActiSleep-BT triaxial accelerometers }(\text { ActiGraph } \\
\text { (®). Each participant wore the device for seven consecutive days. They wore the device } \\
\text { on the right side of the waist fixed by an adjustable and elastic belt. Participants received the following instructions about the device: a) they should wear } \\
\text { during all day and every day for seven days; b) they could remove the device for sleeping, but they should put it back on as soon as they woke up; and c) they } \\
\text { should not use the equipment in activities with water, such as a bath. The selected sampling rate was } 100 \mathrm{~Hz} \text {. Accelerometer's data with at least ten hours of } \\
\text { use per day and used for at least three days (two weekdays and one weekend day) were considered valid data. Records with } 60 \text { consecutive zero minutes were } \\
\text { considered as non-use. After downloading the information for each accelerometer, epoch parameters of five seconds were used, and no bouts were used. The }\end{array}$ \\
\hline
\end{tabular}

Anthropometric Indicators of Overweight and Obesity (AIO)

Four different AIO were analyzed: body mass index (BMI), waist circumference (WC), waist-to-height ratio (WHtR), and the sum of subscapular and tricipital skinfold thickness $(\Sigma \mathrm{ST})$. All measurements were taken twice to obtain the average value for further data analysis and were performed according to standard procedures. BMI was calculated [body mass $/$ height ${ }^{2}\left(\mathrm{~kg} / \mathrm{m}^{2}\right)$ ] using participants' data of body weight and height. WC was measured with the children in a standing position employing a flexible non-elastic metallic tape measure (Cescorf, Porto Alegre, Brasil) positioned midway between the tenth rib and the iliac crest of children to the nearest $0.1 \mathrm{~cm}^{14}$. WHtR was calculated as $\mathrm{WC}(\mathrm{cm})$ divided by height $(\mathrm{cm})$. The subscapular and tricipital ST were measured using a scientific adipometer (Cescorf, Porto Alegre, Brasil) to the nearest 0.1 millimeter $(\mathrm{mm})^{21}$. When the second measure presented a difference in value higher than $10 \%$, one more measure was taken, and the average value of the two closer measures was considered for analyzes.

\section{Secondary Health Outcomes \\ Cardiometabolic Health Indicators}

The group of health indicators included blood pressure (BP), total cholesterol (TC), and fasting glucose (FG).

TC and FG were measured with a portable monitor (Accutrend Plus, Roche Diagnostics) from a drop of capillary blood taken from the fingertip. The results were noted to the nearest one milligram per deciliter $(\mathrm{mg} / \mathrm{dl})$ of blood. Fasting was not required for measuring TC since it shows no significant variation with the individual either fasting or not ${ }^{22}$. Children were fasting from eight to 10 hours to measure FG. BP measurements were performed using a validity ${ }^{23}$ digital device for blood pressure checking (Omron HEM 742) and were noted to the nearest one millimeter of mercury (mm/ $\mathrm{Hg}$ ). The measurements were taken with children at rest for at least ten minutes, on the right arm, sitting, and relaxed situation. Three measures were performed with an interval of approximately two minutes, and the last measure's value was considered for analyzes.

Fitness Health Indicators

Fitness health indicators were comprised of cardiorespiratory fitness (CRF), muscular strength endurance (MSE), maximal muscular strength (MMS), and flexibility (Flex). CRF, MSE, and Flex were assessed by the six-minute run/walk test, the 1 min sit-up test, and sit and reach test, respectively, following standard procedures ${ }^{14}$. MMS was measured by maximal hang-grip strength using a hydraulic hand-grip dynamometer (Jamar; Smith and Nephew, Memphis, $\mathrm{TN}$ ) following the recommendation of the American Society of Hand Therapists ${ }^{24}$.

\section{Behavioral Health Indicators}

In addition to the accelerometer-based PA, other health behaviors were assessed: Participation in structured PA (besides physical education classes); the most enjoyable activity at leisure time; time spent in sedentary behavior (SB); screen time (ST); food habits (FH); and, sleep habits (SH). The following question assessed participation in structured PA: Besides physical education classes, do you practice any PA or sports oriented by a teacher or a coach? For positive answers (yes), children informed which PA or sports was practiced, how many days a week it was performed; and, how long (minutes) each session lasted. The most enjoyable activity at leisure time was assessed by the following question: What do you prefer to do during your free time? The possible answers were: watching TV, electronic games; being with friends; practice some PA or sports. For those who chose for the last option, it was asked what PA or sports. SB was assessed by the valid information from accelerometers' data according to the cut-off points proposed by Evenson et al.$^{20}$. ST was assessed by the children's report about average daily time (week and weekend) watching TV; playing video games; using a computer, smartphone and tablets for fun (free time); and using computer, smartphone, and tablets for study or school activities. FH were assessed by the children's report about the weekly frequency of eating fruit, vegetables, sweets, and soft drinks ${ }^{25}$. In addition, children were asked if they usually had breakfast. SH were assessed by children's quantity and quality of sleep and sleepiness degree. Quantity was considered by the time children reported usually going to bed and waking up (week and weekend days). Sleep quality was assessed by children's perception (always, sometimes, or never) about: sleeping well; waking up in the morning is difficult; sleeping much; sleeping little; falling asleep at night is difficult; waking up in the morning before the time I need; waking during the night; having a restless sleep; and, having nightmares. Sleepiness degree was measured by a ten-point scale where the lowest point corresponds to a low sleepiness level and point 10 to much sleepiness ${ }^{26}$.

Psychological Health Indicators

This set of indicators were comprised of motivation to sports practice (MSP), physical self-concept (PSC), PA enjoyment (PAE), and, depressive symptoms (DS). The Participation Motivation Questionnaire ${ }^{27}$ assessed MSP. The questionnaire comprises 30 items of possible reasons for children's sports practice grouped in eight motivation factors. Children choose the degree of importance for practicing sports of each item according to a five-point Likert scale $(1=$ nothing important; 5 = very important). PSC was measured by the Physical Self-Concept questionnaire ${ }^{28}$, comprised of 36 questions grouped in six factors. In each factor that comprises the questionnaire, there is a five-point Likert scale ( $1=$ Disagree totally; $5=$ Agree totally). EPA was assessed by the Physical Activity Enjoyment Scale ${ }^{29}$.The questionnaire has 16 items about the pleasure to practice PA. In its outline, the children indicate the degree of agreement that most applies to their PA practice using a five-point Likert scale ( $1=$ Disagree totally; $5=$ Agree totally). DS was assessed by Child Depression Inventory ${ }^{30}$. The instrument is comprised of 27 items that verify the presence and severity of depressive symptoms. In each question, the children answer what best describes their feelings regarding the last two weeks on a scale that varies from zero to two points.

(pre- and post-intervention); f) minimal correlation between repeated measures of 0.5 ; and; g) sphericity correction equal to 1.0. The estimated sample size was 138 participants (69 for IG and 69 for $\mathrm{CG}$ ).

\section{Statistical Considerations}

Firstly distributions normality of all numerical variables will be tested (Shapiro-Wilk test) and will be described using mean and standard deviation (parametric distri- 
bution) or median and interquartile difference (non- parametric distribution). Categorical variables will be described using absolute and relative frequencies. To test the effect of the SHOW's intervention program on primary and secondary outcomes the Generalized Estimating Equations (GEE) followed the post-hoc Bonferroni will be used for the comparison between moments and groups and for the identification of the group*moment interaction. Analyzes will be performed by intention to treat (ITT) and by protocol. In the ITT analyzes all participants will be included. In the protocol analyzes, participants who present the measured outcomes in both moments (pre- and post-interven- tion) and those who have participated at least in 70\% of intervention program sessions (IG) will be included.

\section{Discussion}

This article has described the methodological approach of the SHOW study, which aimed to examine the effects of a multicomponent intervention on health markers of overweight children. Carrying out a multicomponent intervention for children in this body condition is an essential methodological feature that should be highlighted. Overweight children are more likely to present a lower profile of physical, social, and psychological health markers than normal-weight children ${ }^{3,6}$.

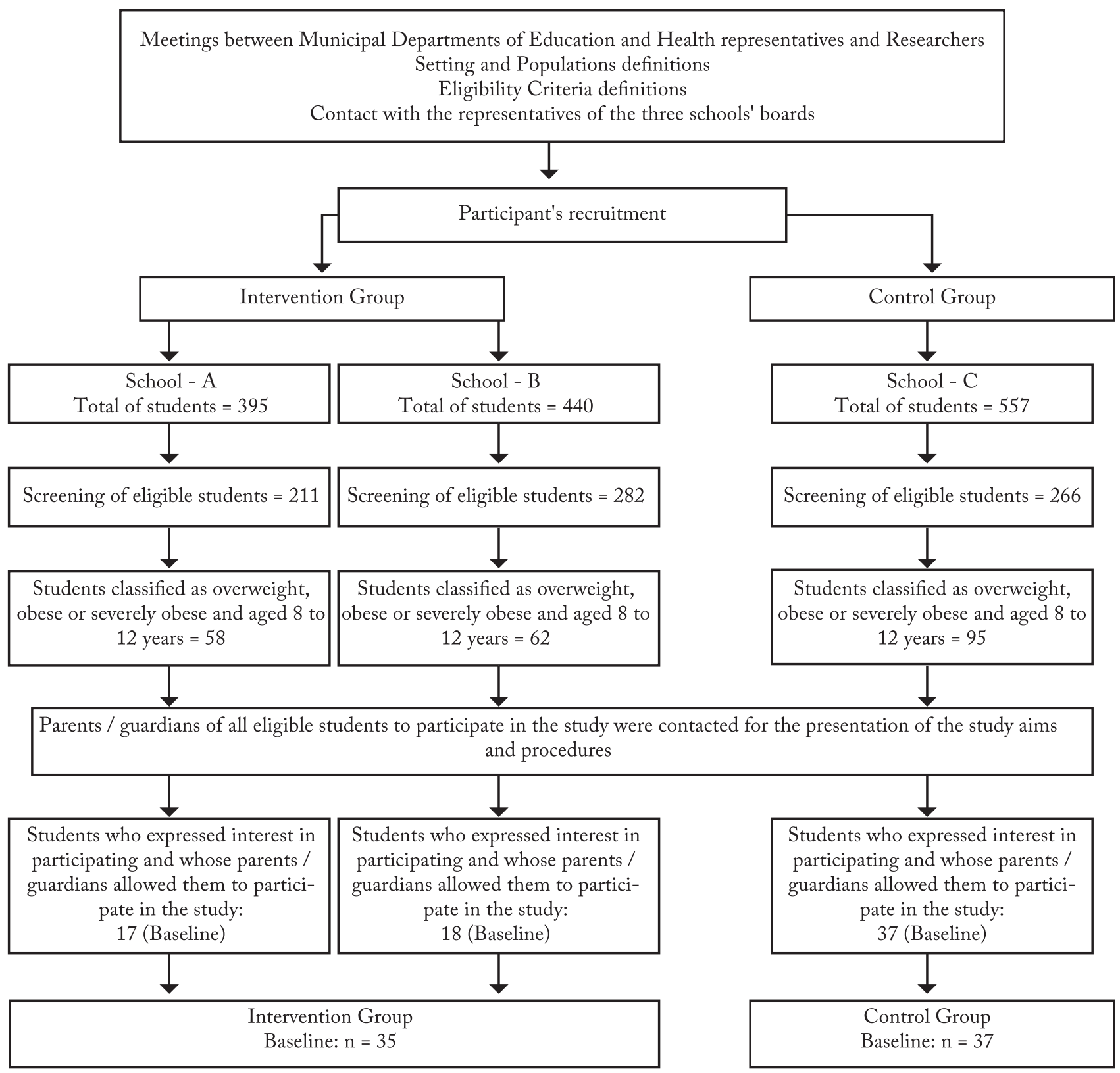

Figure 1 - Flowchart of SHOW study steps for recruitment and enrollment of the participants. 
The structure of the SHOW study was carefully planned to improve participants' health markers. The three components included in the SHOW study increased the likelihood of a successful intervention to improve children's health markers ${ }^{2,4}$. In addition, each of these components presented features that expanded the possibilities to apply the SHOW study in different social contexts. Besides, the fact that the intervention took place in public spaces close to children's homes was another strength of this study. This characteristic may contribute to empower children to use the public space to practice physical activities, and recognize its value as a leisure space.

Although the IG and CG were not randomly allocated, the groups may be similar at the baseline due to the procedures used for the selection of the CG's participants. This is important for interpretations regarding the effects of the SHOW study on post-intervention results.

\section{Conflict of interest}

The authors declare no conflict of interest.

\section{Author's contributions}

Bergamnn GG participated in all stages of the study. Silva LR participated in the conception of the study and in the elaboration of the intervention proposal and carried out a critical review of the content. Ribeiro FS, Botelho VH and Cunha GB participated in the preparation of the proposal for generalized sport initiation and critically reviewed the content. Ferreira GD, and Pinheiro ES, contributed to the writing of the manuscript and critical review of the content. All authors approved the final version of the manuscript.

\section{References}

1. NCD Risk Factor Collaboration (NCD-RisC). Worldwide trends in body-mass index, underweight, overweight, and obesity from 1975 to 2016: a pooled analysis of 2416 population-based measurement studies in 128.9 million children, adolescents, and adults. Lancet. 2017;390(10113):2627-42.

2. A Hamid MS, Sazlina SG. Interventions for obesity among schoolchildren: A systematic review and meta-analyses. PLoS One. 2019;14(1):e0209746.

3. García-Hermoso A, Ramírez-Vélez R, Saavedra JM. Exercise, health outcomes, and pædiatric obesity: A systematic review of meta-analyses. J Sci Med Sport. 2019;22(1):76-84.

4. Li XH, Lin S, Guo H, Huang Y, Wu L, Zhang Z, et al. Effectiveness of a school-based physical activity intervention on obesity in school children: a nonrandomized controlled trial. BMC Public Health. 2014;14:1282.

5. Kelleher E, Davoren MP, Harrington JM, Shiely F, Perry IJ, Mchugh SM. Barriers and facilitators to initial and continued attendance at community-based lifestyle programmes among families of overweight and obese children: a systematic review. Obes Rev. 2017;18(2):183-94.
6. Poitras VJ, Gray CE, Borghese MM, Carson V, Chaput JP, Janssen I, et al. Systematic review of the relationships between objectively measured physical activity and health indicators in school-aged children and youth. Appl Physiol Nutr Metab. 2016;41(6 Supp1 3):S197-S239.

7. Coll CV, Knuth AG, Bastos JP, Hallal PC, Bertoldi AD. Time trends of physical activity among Brazilian adolescents over a 7-year period. J Adolesc Health. 201;54(2):209-13.

8. Faude O, Kerper O, Multhaupt M, Winter C, Beziel K, Junge A, et al. Football to tackle overweight in children. Scand J Med Sci Spor. 2010;20(Suppl 1):103-10.

9. Eime RM, Young JA, Harvey JT, Charity MJ, Payne WR. A systematic review of the psychological and social benefits of participation in sport for children and adolescents: informing development of a conceptual model of health through sport. Int J Behav Nutr Phys Act. 2013;10:98.

10. Seabra AC, Seabra AF, Brito J, Krustrup P, Hansen PR, Mota $\mathrm{J}$, et al. Effects of a 5-month football program on perceived psychological status and body composition of overweight boys. Scand J Med Sci Sports. 2014;24(Suppl 1):10-6.

11. Seabra A, Katzmarzyk P, Carvalho MJ, Seabra A, CoelhoE-Silva M, Abreu S, et al. Effects of 6-month soccer and traditional physical activity programmes on body composition, cardiometabolic risk factors, inflammatory, oxidative stress markers and cardiorespiratory fitness in obese boys. J Sports Sci. 2016;34(19):1822-9.

12. Schulz KF, Sox HC, Rockhold FW, Rennie D, Moher D. SPIRIT 2013 statement: defining standard protocol items for clinical trials. Ann Intern Med. 2013;158(3):200-7.

13. Ryan RM, Deci EL. Intrinsic and extrinsic motivation from a self-determination theory perspective: Definitions, theory, practices, and future directions. Contemp Educ Psych. 2020;61:101860.

14. Gaya ACA, Gaya AR. Projeto esporte Brasil: manual de testes e avaliação. Porto Alegre: UFRGS, 2016. Disponível em: <https://www.ufrgs.br/proesp/arquivos/manual-proespbr-2016.pdf> [julho 2021].

15. Cole TJ, Lobstein T. Extended international (IOTF) body mass index cut-offs for thinness, overweight and obesity. Pediatr Obes. 2012;7(4):284-94.

16. Greco PJ. Metodologia do ensino dos Esportes Coletivos: Iniciação Esportiva Universal, Aprendizado IncidentalEnsino Intencional. R Min Educ Fís. 2012;20(2):145-74.

17. Kirk D, MacPhail A. Teaching Games for Understanding and Situated Learning: Rethinking the Bunker-Thorpe Model. J Teach Phys Educ. 2002;21(2):177-92.

18. Ørntoft C, Fuller CW, Larsen MN, Bangsbo J, Dvorak J, Krustrup P. 'FIFA 11 for Health' for Europe. II: effect on health markers and physical fitness in Danish schoolchildren aged 10-12 years. Br J Sports Med. 2016;50(22):1394-99.

19. Mirwald RL, Baxter-Jones AD, Bailey DA, Beunen GP. An assessment of maturity from anthropometric measurements. Med Sci Sports Exerc. 2002;34(4):689-94.

20. Evenson KR, Catellier DJ, Gill K, Ondrak KS, McMurray RG. Calibration of two objective measures of physical activity for children. J Sports Sci. 2008;26(14):1557-65.

21. Slaughter MH, Lohman TG, Boileau RA, Horswill CA, Stillmann RJ, Van Loan MD. Skinfold equations for estimation of body fatness in children and youth. Hum Biol. 1988;60:709-23.

22. Xavier HT, Izar MC, Faria Neto JR, Assad MH, Rocha VZ, Sposito AC, et al. V Diretriz Brasileira de Dislipidemias e Prevenção da Aterosclerose. Arq Bras Cardiol. 2013;101(4 Suppl 1):1-20. 
23. Christofaro DGD, Fernandes RA, Gerage AM, Alves M J, Polito MD, Oliveira AR. Validação do monitor de medida de pressão arterial Omron HEM 742 em adolescentes. Arqui Bras Cardiol. 2009;92(1):10-5.

24. Roberts HC, Denison HJ, Martin HJ, Patel HP, Syddall $\mathrm{H}$, Cooper C, et al. A review of the measurement of grip strength in clinical and epidemiological studies: towards a standardised approach. Age Ageing. 2011;40(4):423-9.

25. Currie C, Griebler R, Inchley J, Theunissen A, Molcho M, Samdal Oet al \& (eds.). Health Behaviour in Schoolaged Children (HBSC) Study Protocol: Background, Methodology and Mandatory Items for the 2009/10 Survey. Edinburgh: CAHRU \& Vienna: LBIHPR, 2010. Disponível em: <http://www.hbsc.org/methods> [julho 2021].

26. Matos MG, Equipa Aventura Social. A Saúde dos Adolescentes após a Recessão - Dados nacionais 2018. Lisboa: Projeto Aventura Social \& Faculdade de Motricidade Humana/Universidade de Lisboa, 2018. Disponível em: <http://aventurasocial.com/publicacoes/ publicacao_1545534554.pdf> [julho 2021].
27. Guedes DP, Silvério Netto JE. Participation Motivation Questionnaire: tradução e validação para uso em atletas-jovens brasileiros. Rev Bras Educ Fís Esporte. 2013;27(1):137-48.

28. Goñi A, Ruiz de Azua S, Liberal,I. Propiedades psicométricas de un nuevo cuestionario para la medida del autoconcepto físico. Rev de Psicol del Deporte. 2004;13(02):195-213.

29. Motl RW, Dishman RK, Saunders R, Dowda M, Felton G, Pate RR. Measuring enjoyment of physical activity in adolescent girls. Am J Prev Med. 2001;21(2):110-7.

30. Kovács M. The Children`s Depression Inventory: A self-rated depression scale for school - aged youngsters. University of Pittsburg School of Medicine, Pittsburgh. 1983.

Received: 03/08/2021

Approved: 23/09/2021

\section{Quote this article as:}

Bergmann GG, Silva LR, Ribeiro FS, Botelho VH, Cunha GB, Ferreira GD, Pinheiro ES. Methodological approach of Sport and Health for Overweight children (SHOW) intervention study. Rev Bras Ativ Fis Saúde. 2021;26:e0224. DOI: 10.12820/rbafs.26e0224 